Marquette University

e-Publications@Marquette

College of Education Faculty Research and

Publications

Education, College of

$10-1-2003$

\title{
African American and European American Therapists' Experiences of Addressing Race in Cross-Racial Psychotherapy Dyads
}

Sarah Knox

Marquette University, sarah.knox@marquette.edu

Alan W. Burkard

Marquette University, alan.burkard@marquette.edu

Adanna Jinaki Johnson

Marquette University

Lisa A. Suzuki

New York University

Joseph G. Ponterotto

Fordham University

Accepted version. Journal of Counseling Psychology, Vol.50, No. 4 (October 2003): 466-481. DOI.

This article may not exactly replicate the final version published in the APA journal. It is not the copy of record. 


\title{
African American and European American Therapists' Experiences Of Addressing Race in Cross-Racial Psychotherapy Dyads
}

\author{
Sarah Knox \\ Department of Counseling and Educational Psychology \\ School of Education, Marquette University \\ Milwaukee, WI \\ Alan W. Burkard \\ Department of Counseling and Educational Psychology \\ School of Education, Marquette University \\ Milwaukee, WI \\ Adanna J. Johnson \\ Department of Counseling and Educational Psychology \\ School of Education, Marquette University \\ Milwaukee, WI \\ Lisa A. Suzuki \\ Department of Applied Psychology, School of Education, New \\ York University \\ New York, NY \\ Joseph G. Ponterotto \\ Division of Psychological and Educational Services, Graduate \\ School of Education, Fordham University \\ New York, NY
}


NOT THE PUBLISHED VERSION; this is the author's final, peer-reviewed manuscript. The published version may be accessed by following the link in the citation at the bottom of the page.

Using Consensual Qualitative Research, 12 licensed psychologists' overall experiences addressing race in psychotherapy were investigated, as were their experiences addressing race in a specific cross-racial therapy dyad. Results indicated that only African American psychologists reported routinely addressing race with clients of color or when race was part of a client's presenting concern. European American psychologists indicated that they would address race if clients raised the topic, and some reported that they did not normally address race with racially different clients. When discussing a specific cross-racial dyad, African American therapists more often than European American therapists addressed race because they perceived client discomfort. Only European American therapists reported feeling uncomfortable addressing race, but therapists of both races perceived that such discussions had positive effects.

Imagine that you are working with a client of a different race from your own. How do you decide whether and, if so, when and how to address the topic of race in the therapy? If you do address race, how does the conversation affect the therapy; if you do not address race, what is the effect of this decision? These were a few of the questions that guided the present study, for such decisions may well have a great impact on therapy.

\section{Theoretical and Empirical Background}

Theorists have suggested that therapist responsiveness to cultural issues, including race, is important to the development of effective cross-cultural therapy relationships (e.g., Atkinson \& Lowe, 1995; Boyd-Franklin, 1989; Helms, 1984; Pinderhughes, 1989; Sue \& Sue, 2002). Cultural responsiveness in therapy occurs when the therapist responds to the cultural content present in a counseling session. Counselors who demonstrate cultural responsiveness in therapy "acknowledge the existence of, show interest in, demonstrate knowledge of, and express appreciation for the client's ethnicity and culture ... [and] ... place the client's problem in a cultural context" (Atkinson \& Lowe, 1995, p. 402). Although the importance of cultural responsiveness in therapy has been theoretically recognized in the development and adoption of the American Psychological Association's (APA) "Guidelines for Providers of Psychological Services to Ethnic, Linguistic, and Culturally Diverse Populations" (American Psychological Association, 1993), as well as the more recent adoption of "Guidelines on Multicultural Education, Training, Research, Practice, and Organizational Change for Psychologists" (American Psychological 
Association, 2003), current empirical research into how such responsiveness actually occurs in therapy and how it affects real therapy relationships remains in its infancy. The importance of such research has been clearly articulated in the acknowledgment of the field's need to translate theoretical concepts into usable therapy techniques (Burkard, Juarez-Huffaker, \& Ajmere, in press; Burkard, Ponterotto, Reynolds, \& Alfonso, 1999; Fuertes \& Gretchen, 2001).

Much of the research that does exist on cultural responsiveness is analogue and suggests that therapists who are responsive to cultural issues in therapy are consistently perceived by persons of color (i.e., African Americans, Asian Americans, Mexican Americans) as more credible and more culturally competent than therapists who are not culturally responsive in therapy (Atkinson, Casas, \& Abreu, 1992; Gim, Atkinson, \& Kim, 1991; Pomales, Claiborn, \& Lafromboise, 1986). Additionally, persons of color report more satisfaction with counseling and return for more counseling sessions when counselors are more culturally responsive in therapy than culturally unresponsive (Wade \& Bernstein, 1991). Cultural responsiveness has been variously operationalized in these studies as counselors responding to cultural content either by acknowledging the role of culture/ethnicity in a client's concern or as counselor responses demonstrating knowledge of a client's culture (Atkinson et al., 1992); appropriate empathy and acknowledgment of the importance of ethnicity and cultural values in clients' experiences, as well as expression of an interest in exploring such values and experiences further (Gim et al., 1991; Pomales et al., 1986); and completion of 4 hr of culture sensitivity training (Wade \& Bernstein, 1991). These preliminary research findings suggest that in analogue designs, counselors who address cultural issues facilitate positive client outcomes. Researchers have a limited understanding, however, of the effects of such responsiveness in nonanalogue (i.e., real) counseling dyads (Ponterotto, Fuertes, \& Chen, 2000).

Additionally, these prior investigations focused on the more global concept of culture, as seen in the use and definition of cultural responsiveness. However, the study participants were identified by ethnicity and race, factors more specific than culture. Furthermore, although some therapists were perceived by participants as being culturally responsive, it remains unclear whether they were also racially responsive. In other words, it is possible that these therapists' 
cultural responsiveness included attention to a variety of factors (e.g., acculturation, culture, ethnicity, gender, religion, sexual orientation). Reflective of this concern, Helms and her colleagues asserted that attention to the broader construct of multiculturalism may actually diffuse attention to the more specific construct of race (Carter, 1995; Helms, 1995; Helms \& Cook, 1999; Helms \& Richardson, 1997). Clients may perceive this potentially lesser focus on race not only as minimizing the salience of their racial identity but also as minimizing the impact of racism that they may have experienced, and thus affecting therapy relationships in which these clients are involved (Carter, 1995; Helms, 1984). We, then, chose to focus this study on therapists' responsiveness to race in therapy and defined race as a "category of persons who are related by a common heredity or ancestry and who are perceived and responded to in terms of external features or traits" (Wilkinson, 1993, p. 19).

Researchers' understanding of the effects of racial responsiveness is even more limited than that of cultural responsiveness in therapy. The few researchers who specifically focused on race, not the more global construct of culture (as described above), have found that discussions of race significantly affect the therapeutic process. Unfortunately, none actually operationalized the construct of racial responsiveness. In an analogue study, Thompson, Worthington, and Atkinson (1994) found that "pseudoclients" (i.e., 100 African American female undergraduate students who volunteered to participate in the study) tended to self-disclose more intimately when counselors (i.e., African American or European American) directly asked about clients' experiences of being Black women on a predominantly White campus. In a qualitative extension of Thompson et al.'s (1994) work, Thompson and Jenal (1994) focused on African American women pseudoclients who raised or did not raise racial issues in counseling. The researchers examined their participants' reactions to African American and European American counselors who avoided facilitation of discussions related to racial content and found that those women who raised racial issues tended to become frustrated and exasperated with counselors who avoided racial content. In another qualitative study, Fuertes, Mueller, Chauhan, Walker, and Ladany (2002) asked European American counselors to discuss a recent or current successful therapy experience with an African American client. The researchers found that therapists' directly 
addressing racial issues in the first two sessions of a 12-session counseling experience created an environment conducive to establishing a strong therapeutic relationship. Additionally, Zhang and Burkard (2002) found in their field study that clients who perceived their therapists as racially responsive rated the working alliance significantly higher than clients who perceived their therapists as racially unresponsive in therapy. Collectively, these findings suggest that counselors' racial responsiveness may increase the intimacy of client self-disclosure and may strengthen the therapeutic relationship.

\section{Purpose of Study}

Although previous studies have yielded valuable information regarding the potential impact of discussions of race on the therapeutic relationship, little is known about how, when, and why therapists raise such discussions in counseling. We felt that a qualitative design, namely consensual qualitative research (CQR; Hill, Thompson, \& Williams, 1997), would afford us the opportunity to explore such questions in depth without restricting participants' responses. As Ponterotto (2002) stated, there is increasing momentum for qualitative research in counseling psychology as a whole, a momentum also felt more specifically in multicultural counseling. We sought, then, to interview therapists about their experiences of raising and not raising the topic of race in specific cross-racial dyads (i.e., African American therapist-European American client; European American therapist-African American client). As foundation and context for these experiences, we were also interested in therapists' interactions with racially different individuals before, during, and after graduate school, as well as the usual circumstances in which they did and did not address race in therapy.

We hoped that the results of this study would add to our understanding of how addressing or not addressing race in therapy may affect the therapeutic process and relationship. Such understanding may provide therapists with useful information regarding effective discussion of race and offer ideas for training new therapists to address race in cross-racial dyads. 
NOT THE PUBLISHED VERSION; this is the author's final, peer-reviewed manuscript. The published version may be accessed by following the link in the citation at the bottom of the page.

\section{Method}

\section{Participants}

\section{Therapists}

A geographically diverse sample of 12 licensed psychologists (6 men, 6 women; 5 African American, 7 European American) participated in this study. African American therapists ranged in age from 31 to 53 years $(M=39.0, S D=9.21)$; European American therapists ranged in age from 32 to 54 years $(M=43.0, S D=9.44)$. The African American participants had been in practice for 2-27 years $(M=9.2, S D=9.02 ; M d n=6)$; their European American counterparts had been in practice for $2-16$ years $(M=7.00, S D=4.66$; $M d n=5)$. African American participants described their theoretical orientations (nonmutually exclusive) as the following: psychodynamic/interpersonal/developmental/self $(n=5)$, cognitive/cognitive-behavioral $(n=1)$, and eclectic/multicultural ( $n=$ 1). European American participants identified their theoretical orientations (nonmutually exclusive) as the following: psychoanalytic/psychodynamic $(n=3)$, cognitive/cognitive-behavioral $(n=3)$, feminist/systems $(n=2)$, humanistic/existential $(n=2)$, and eclectic/integrated $(n=2)$. African American participants reported that between $10 \%$ and $98 \%(M=74.6, S D=32.9)$ of their current adult individual caseloads consisted of clients who were racially different from themselves. The races of those clients were as follows: Asian American, European American, Latina/o, and Native American. European American participants reported that between 5\% and $20 \%$ $(M=11.57, S D=5.26)$ of their current adult individual caseloads consisted of clients who were racially different from themselves. The races of those clients were as follows: African American, Asian American, biracial, Latina/o, Native American, and Pacific Islander. Finally, the three most common diagnostic categories (nonmutually exclusive) in the African American therapists' adult individual caseloads were depression, anxiety disorders, and adjustment disorders; those for the European American therapists were mood disorders, anxiety disorders, and adjustment disorders. 
NOT THE PUBLISHED VERSION; this is the author's final, peer-reviewed manuscript. The published version may be accessed by following the link in the citation at the bottom of the page.

Interviewers and Judges: Three researchers completed the audiotaped interviews and also served as the primary research team: a 40-year-old European American woman, a 43-year-old European American man, and a 25-year-old African American woman. At the time of the study, two researchers were assistant professors, and the third was a 2nd-/3rd-year graduate student in a counseling psychology doctoral program. A 41-year-old Asian American female associate professor served as one auditor, and a 45-year-old European American male professor served as the second auditor. All were authors of the study.

Before conducting the interviews or analyzing the data, the researchers explored their potential biases and expectations by addressing several questions related to the study (i.e., How did they define multiculturalism? What training and personal experiences had they had regarding multiculturalism, and how useful had these experiences been? How did they bring the topic of race into the therapy interaction? How had their thoughts and feelings about addressing race in therapy changed over the course of their careers?). All 5 authors endorsed a broad conceptualization of multiculturalism, asserting that the construct included not only race but also ethnicity, culture, gender, age, sexual orientation, religion, dis/ability, socioeconomic status (SES), and so forth. Regarding their training experiences, all 5 authors had specific classes in graduate school that addressed multiculturalism, and 2 also indicated that attention to diversity was infused throughout much of their graduate training. Two researchers indicated that they had been supervised by someone of a different race from their own, four reported attending multicultural conferences or workshops, and two cited the influence of a graduate school mentor as helping to form their understanding of multiculturalism. In terms of personal experiences, three authors stated that the time they spent living in a culturally diverse area had affected them, and two also stated that personal relationships with others likewise enhanced their sensitivity to multiculturalism. When discussing their approach to or experience of addressing race in therapy, 1 researcher indicated having had only positive experiences with addressing race; another researcher acknowledged that because she had not seen many racially different clients, she had not raised the topic of race that often; a third researcher stated that she would 
address race if there was a timely opportunity, or if the issue emanated from the client and was relevant to the client, the therapy relationship, or the work of therapy. Two researchers stated that they had become more aware of the impact of race and now felt more comfortable addressing race in therapy. One researcher was struggling with whether she should address race with clients of her same racial background, and another researcher reported that he had become more active and outspoken regarding what he viewed as the ill-effects of endemic "isms" in our society.

\section{Measures}

Demographic Form: The demographic form asked for basic information about participants: age; gender; race/ethnicity; years in practice; theoretical orientation; percentage of clients in current adult individual caseload who were racially different from the therapist, as well as the race(s) of those clients; and the three most common diagnostic categories among this caseload. The form also asked participants to give their name, phone number, and e-mail address to enable contact, as well as specify convenient times for a researcher to call to arrange for the first interview.

Interview Protocol: Consistent with CQR methodology, the protocol reflected a semi-structured interview (i.e., a standard set of questions was asked of all participants, and additional probes were asked depending on an interviewee's responses; see Appendix). The first interview opened with several questions we hoped would form a context within which to understand participants' actual experiences addressing or not addressing race in distinct psychotherapy dyads (e.g., their pregraduate, graduate, and postgraduate experiences related to race; situations in which they would and would not address race in psychotherapy; frequency of addressing racial issues in crossracial therapy dyads). In this first section, then, broad, survey-type questions were used to access therapists' overall experiences with race. In contrast to the interview's broad opening section, the second major section of the interview captured therapists' experiences in specific cross-racial dyads, wherein therapists were asked to describe the following four types of incidents involving adult individual clients: a discussion of race that they perceived to have had a positive effect on 
therapy, a discussion of race that they perceived to have had a negative effect on therapy, a lack of discussion of race that they perceived to have had a positive effect on therapy, and a lack of discussion of race that they perceived to have had a negative effect on therapy. The interview closed with broader questions asking participants about any changes in their thoughts and feelings about addressing race in therapy over the course of their career, advice they would give to those in the field and/or involved in training about this issue, and what thoughts and feelings were evoked by doing the interview itself.

The follow-up interview, scheduled approximately 2 weeks after the initial interview but before any data analysis, provided a chance for the researcher to ask any questions that might have arisen after the initial interview and for the participant to clarify what she or he felt necessary. It also provided a chance for both researcher and participant to explore what, if any, further thoughts and reactions might have been stimulated by the first interview.

\section{Procedures for Collecting Data}

Recruiting Therapists: A snowball sampling technique and listservs were used to obtain participants. In the snowball technique, 19 colleagues known to the primary team were initially contacted and asked to identify as many people as possible, including themselves, who fit the initial parameters for participants (i.e., African American or European American licensed psychologists who had been practicing for between 5 and 15 years). Those so identified $(N=34)$ were contacted by phone and/or mail, indicating how their name was obtained and inviting them to participate. This invitation consisted of describing the study (over the phone) and/or mailing a packet of materials that also described the research (i.e., cover letter explaining the study, consent and demographic forms, initial interview protocol). For those who declined, this ended their involvement; those who accepted were sent the packet of materials (if not already sent). Upon the return of the consent and demographic forms $(n=4)$, the participant was contacted and the first interview was scheduled. Participants were randomly assigned to an interviewer, except when the participant and 
interviewer knew each other; in such cases, the participant was assigned to a different interviewer.

Permission was received from the appropriate Webmasters to seek participants through four listservs (i.e., Divisions 17 and 45 of APA, Association of Black Psychologists, Association of Counseling Center Training Agencies). The coordinator of these listservs was sent a descriptive paragraph about the study, including information for potential participants to contact the researchers. This material was posted on the listserv. Those who contacted the researchers via the listservs $(n=10)$ were then sent the packet of materials. Upon receipt of their consent and demographic forms $(n=3)$, the participants were contacted and the first interview was scheduled.

Through these techniques, approximately half of the sample was obtained. We sought, also, to balance the numbers of African American and European American as well as male and female participants and found that these first attempts yielded more European American and male participants. As a result, the requirement that therapists must have been in practice for 5-15 years was eliminated and the pursuit of both snowball and listserv avenues for the sample was continued. We then were able to obtain the complete sample, as indicated above. One participant completed the interview process but was dropped from data analysis because this psychologist's clinical experiences focused solely on adolescents. Given the process used to recruit participants, a definitive return rate cannot be reported.

In the packet of materials mailed to interested therapists, the cover letter explained that those who agreed to participate would be asked a series of questions about addressing race in therapy in two taped phone interviews, the first lasting less than $1 \mathrm{hr}$, the second lasting less than $30 \mathrm{~min}$. They were assured that their responses would be held confidential via the assignment of code numbers. Those who agreed to participate were asked to complete and return the consent and demographic forms included with the letter. The protocol for the first interview was also included in this mailing, with the hope that it would help potential participants decide whether to participate and stimulate the responses of those who indeed chose to take part in the study. 
Interviewing: All interviewers completed a pilot interview with an individual who fit the study criteria but was not included as an actual participant. These pilots allowed the interviewers to become comfortable with the protocol and address any concerns regarding the mechanics or content of the interview process. Each of the primary team members then completed both the initial and follow-up interviews with 3-5 study participants, using the interview protocol. At the end of each interview, the researcher made notes on the interview, indicating its length and the interviewer's sense of her or his ability to build rapport with the participant. At the conclusion of the approximately 30-60-min first interview, a time for the brief follow-up interview was scheduled. At the close of the 5-15-min follow-up interview, each interviewer asked her or his participants whether they were willing to receive and comment on a draft of the final results.

Transcripts: The interviews were transcribed verbatim (except for minimal encouragers, silences, and stutters) for each participant. All identifying information was removed from the transcripts, and each therapist was assigned a code number.

Draft of Final Results: Those participants who requested ( $n=$ 12) were sent a draft of the final results. They were asked to comment on the degree to which their own experiences had been captured by the group results presented in the draft. In addition, they were asked to verify that their confidentiality had been maintained in any examples included in the results. Four participants responded: 3 suggested no changes to the results, and 1 suggested a minor change, which was made.

\section{Procedures for Analyzing Data}

The data were analyzed with CQR methods (Hill et al., 1997). Fundamental to this qualitative methodology is reaching consensus regarding the meaning and categorization of the data. Such consensus is pursued by team members initially discussing their individual conceptualizations and then agreeing on a final understanding that all find satisfactory. Early disagreement is the norm and is then worked through until eventual agreement (consensus) is obtained. 
NOT THE PUBLISHED VERSION; this is the author's final, peer-reviewed manuscript. The published version may be accessed by following the link in the citation at the bottom of the page.

Coding of Domains: The primary team initially developed a "start list" (Miles \& Huberman, 1994) of domains (topic areas) by grouping the questions from the interview protocol. These domains were altered as the team worked through the transcripts, and further modifications occurred throughout the analysis process to reflect emerging data. The final domains appear in Tables 1 and 2. Using the transcripts, the three judges individually assigned each meaning unit (a complete thought, ranging from a phrase to several sentences) from each transcript into its appropriate domain(s). The judges discussed meaning units' assignment into domains until they reached consensus.

Coding of Core Ideas: Each judge then independently read all data within each domain for a specific case and identified what she or he considered to be the core ideas that reflected the data content in more concise terms. Judges discussed each core idea until they reached consensus regarding content and wording. The auditors then checked the resulting consensus version of each case and inspected the accuracy of both the domain coding and the wording of the core ideas. The judges then discussed the auditors' remarks and again arrived at consensus for the domain coding as well as the wording of the core ideas.

Cross-Analysis: Initial cross-analyses were completed on 10 of the 12 cases, following the method outlined by Hill et al. (1997). Each member of the primary team examined the core ideas from all cases for each domain and individually developed categories that best captured these core ideas. The team then arrived at consensus on the conceptual labels (titles) of the categories and the core ideas that belonged in each category. Next, the judges returned to the consensus versions of each case to determine whether the cases contained data not previously coded for any of the categories. Categories and domains were thus revised until the judges agreed that the data were well represented. The auditors then reviewed the cross-analysis. Their suggestions were considered by the primary team and incorporated if agreed on by consensus, resulting in a revised cross-analysis. Finally, the auditors reviewed this revised cross-analysis. 
Stability Check: After the initial cross-analysis was complete, the remaining two cases (omitted in the initial cross-analysis; see above) were added back in to determine whether the designations of "general," "typical," and "variant" (see below) changed, and also to assess whether the team felt that new categories were warranted to accommodate the final two cases. The remaining cases did not alter the results substantially, and hence the findings were deemed stable. Categories were labeled general if they applied to all cases, typical if they applied to at least half (but not all) of the cases, and variant if they applied to fewer than half but at least two cases. Core ideas that fit for only one case were placed into the "other" category for that domain.

\section{Results}

We first present the findings that emerged from therapists' remarks about their overall experiences with racially different individuals and with race in therapy (i.e., not tied to a specific racially different client; see the Therapists' Overall Experiences With Race section; see also Table 1). These findings form a necessary context and foundation on which readers may understand the subsequent results. Next, we present the results that emerged when therapists discussed addressing or not addressing race with a specific racially different client (see the Therapists' Discussion of a Specific CrossRacial Dyad section; see also Table 2). Finally, we present illustrative examples to convey representative experiences of therapists addressing or not addressing race in cross-racial therapy dyads.

We also have chosen to present these results distinctly for our racially split sample. In each domain, then, we first present results for African American participants and next present results for European American participants. We have elected this means of presentation because it more clearly highlights the different experiences reported by these two participant groups. Were we to present the combined findings, we feared that such differences would be obscured in that merging. Thus, although the categories that emerged were largely consistent between the two therapist groups, the frequency of endorsement (i.e., general, typical, variant) often differed meaningfully. 
NOT THE PUBLISHED VERSION; this is the author's final, peer-reviewed manuscript. The published version may be accessed by following the link in the citation at the bottom of the page.

Finally, although the interview questions were focused specifically on race, many participants responded more globally in terms of multiculturalism as a whole, which includes other constructs in addition to race. Thus, in the results reported in the Therapists' Overall Experiences With Race section, the categories often reflect this broader conceptualization of multiculturalism. In the Therapists' Discussion of a Specific Cross-Racial Dyad section, however, the categories reflect therapists' comments specifically related to experiences with a racially different client (i.e., African American therapist-European American client dyad, European American therapist-African American client dyad).

\section{Therapists' Overall Experiences With Race}

\section{Experiences With Racially Different Individuals Prior to} Graduate School: One general and one variant category emerged for African American therapists. All of these participants reported having pregraduate school experiences with people of different races through which they learned about race. One therapist, for example, stated that her experience in a university's summer program to encourage minority students' involvement in research put a "fire under [her] butt" with respect to her awareness of the injustice of looking at behavior only from a Eurocentric point of view and ignited her passion for multiculturalism. Another therapist, whose ancestors had been freed by Quakers during the Revolutionary War and were "freed men living in a slave society," was raised in the "segregated South" where he was highly aware of "a lore, a tradition ... about how Black people survive in a hostile environment." A third therapist, who had no prior positive experiences with White men, as an undergraduate did have a positive interaction with a White male, which helped this therapist see that "all White males were not abusive police officers or people who were abusive of their authority." In the variant category, these participants reported that such experiences influenced how they approached psychotherapy. As an illustration, 1 respondent stated that these experiences shaped how she related to clients in terms of identity models.

European American therapists typically reported having pregraduate school experiences with people of different races through 
which they learned about race. One participant indicated that he had lots of close friendships with people of various races as a child and young adult and felt that these relationships helped him break down his false stereotypes and prejudice based on society or family influence. Another therapist reported that she had many African American friends as a child and was also quite close to her African American nanny, who essentially raised her. Through learning about her nanny's life, the therapist became aware of White privilege and its implications for herself and others. As a variant category, European American therapists acknowledged their early naiveté about or denial of racial issues. Here, for example, 1 participant stated that although as a child he learned to treat everyone the same (e.g., kids of different ethnicities were just his friends; it was "no big deal"), as an adult professional he had moved away from his naive earlier position and now placed more emphasis on a person's cultural heritage, realizing that it can be "a big deal" for that person.

\section{Experiences Regarding Racially Different Individuals During Graduate School}

Didactic: African American therapists typically reported that they had classes in graduate school within which at least some focus was directed toward multicultural issues. One participant stated that in addition to a specific graduate course in multiculturalism that all students took, the construct was incorporated into some of his other courses as well. Variantly, these participants reported that they had attended multicultural workshops, interest groups, or received special training in multiculturalism. Here, for instance, 1 participant indicated that she attended multicultural workshops and interest groups that included issues of race and culture as they applied to research and practice.

As did their African American counterparts, European American therapists also typically reported that they had completed classes in graduate school in which there was at least some focus on multicultural issues. One therapist noted that he took a required class addressing multicultural issues in therapy and in society and was also required to take a class focusing on work with a specific multicultural group. As a second typical category, the European American therapists reported having attended multicultural workshops or interest groups, 
or receiving special training in multiculturalism. As an example, 1 therapist indicated that as he became more in control of his education and training, he sought out activities that would support his interest in multiculturalism and challenge his growth in this area. In a category that did not emerge at all for African American therapists, European American participants variantly reported minimal or no class experiences that addressed race. For instance, 1 participant reported that there were no explicit references to race during his academic training.

Supervision or practicum: Two typical and three variant categories emerged for African American participants. First, these therapists typically reported that they had experience working with multicultural populations while on practicum or internship. As an example, 1 therapist stated that she saw clients of diverse backgrounds (e.g., Asian American, Latino, lesbian/bisexual/gay), and another respondent indicated that he completed his internship at a psychiatric hospital with a large French American population. In the second typical category (one that did not emerge at all for European American participants), African American therapists reported that they had negative experiences related to race during their graduate school practica or supervision. Here, for instance, 1 therapist felt that she was representing all Black women to her White supervisors and also stated that she felt it unsafe to disagree with her White supervisors. Another therapist described working with a White client who was very angry and stressed. The therapist felt that the client would experience therapeutic benefit if she (the client) were to scream, but he did not allow this to happen because of his fears of how he would be perceived as an African American man with a screaming European American woman at a predominantly European American counseling center. As the first variant category here, African American therapists reported having significant experiences in supervision about multiculturalism. One participant reported, for instance, that multicultural issues were infused throughout his supervision. Second, these therapists variantly reported that they participated in multicultural training activities as predoctoral interns. Here, 1 respondent stated that she had an hourlong cross-cultural seminar each week as an intern, she cofacilitated a cultural communication class for undergraduate peer counselors, and participated in the counseling center's cross-cultural committee. Finally, these participants variantly reported receiving minimal or no 
supervision or practica-related experiences addressing race. One therapist stated that all of her supervisors were European American, and none of them addressed race directly in a way that the respondent felt was knowledgeable or competent.

Among the European American therapists, two typical and two variant categories emerged. First, these therapists typically reported that, like their African American counterparts, they had experiences with multicultural populations while on practica or internship. As an illustration, 1 therapist indicated that in both her practica and supervision, she worked with individuals of different races from herself. In the second typical category, however, these therapists stated that they had minimal or no supervision or practica-related experiences addressing race. Here, for example, 1 therapist reported that he had some supervisors who did not see race as relevant and did not engage racial issues in supervision. In the first variant category, European American therapists stated that they had significant experiences in supervision regarding multiculturalism. One therapist here, for example, stated that he had some supervisors who were "very good and very focused" on multiculturalism. Finally, these participants variantly reported that they took part in multicultural training during their predoctoral internship, as illustrated by the therapist who described receiving "more sophisticated training during internship on racial issues" as compared with her practica.

\section{Postgraduate School Experiences Regarding Racially Different Individuals}

Didactic: One general and one typical category emerged, neither of which emerged for European American respondents. All of the African American therapists indicated that, after completing their graduate training, they had participated in workshops or conferences focusing on multiculturalism. In addition, they typically reported having conducted training sessions or discussion groups focused on multiculturalism. One taught a multicultural counseling course, another provided didactic training for interns, and a third ran discussion groups for undergraduates specifically focusing on racial and cultural differences. 
NOT THE PUBLISHED VERSION; this is the author's final, peer-reviewed manuscript. The published version may be accessed by following the link in the citation at the bottom of the page.

Among the European American therapists, only one variant category emerged: They reported minimal or no postgraduate didactic experiences that focused on race. One therapist, in fact, stated that although he has had quite a bit of postgraduate education (in a psychoanalytic institute), none has focused on race in therapy. He further reported that he learned most of what he knows about race through the licensing review materials.

Supervision: One category emerged for African American participants: They typically reported having had multicultural experiences as part of their supervised postgraduate position (a category that did not emerge for European American therapists). One therapist, for instance, supervised a European American male intern with whom she discussed racial issues.

In the only category to emerge for European American respondents, participants typically reported having had minimal or no postgraduate supervision experiences that focused on race. For example, 1 therapist stated that racial issues were not a focus of his postdoctoral supervision.

\section{Circumstances in Which Therapists Do Address Race in} Psychotherapy: For African American therapists, one general, one typical, and one variant category emerged here. All of these therapists reported that they would address race when they felt it was relevant to the process or relationship of therapy. As an example, 1 respondent stated that she addressed race when she felt that race-related issues were coming up in therapy; another therapist indicated that she addressed race if she sensed an "elephant in the room" that was not being discussed. These therapists also typically addressed race with clients of color, a category that did not emerge at all for European American participants. Here, for instance, 1 therapist stated that he addressed race "with all clients of color" during his intake procedures because he worked at a predominantly European American university in a similarly European American city. In the variant category (again, one that did not emerge for the European American sample), these respondents stated that they addressed race when it was part of a client's presenting concern. For example, 1 therapist reported that she addressed race when clients discussed experiences of discrimination, 
and another commented that he addressed race when it "figured prominently in the problems which brought about [client] symptoms."

Results for European American therapists yielded one typical and two variant categories (neither of the variant categories emerged for the African American sample). As a typical category, these participants stated that, like their African American counterparts, they would address race when they deemed it relevant to the therapy process or relationship. One therapist, for instance, indicated that if he sensed that something was blocking his work with a racially different client, he "may raise racial differences as a possibility;" another therapist acknowledged that she has discussed with clients how it might feel to talk about personal issues with a racially different therapist. In the first variant category, these participants reported that if a client raised the topic of race, the therapist would respond and continue the dialogue. For example, 1 therapist reported that she tended to wait to see whether her clients raised race as an issue. In the final variant category, European American therapists reported that they would not normally pursue racial issues in therapy. As an illustration, 1 participant stated that he "would generally not raise or discuss" the topic of race in therapy.

\section{Circumstances in Which Therapists Do Not Address Race in} Psychotherapy: Now examining those circumstances in which African American therapists do not address race in therapy, one typical and two variant categories emerged. These therapists typically did not address race if they deemed it not an issue in therapy. For example, 1 participant stated that she does not address race systematically or automatically when working with a client of a different race, because "race can be irrelevant to the client's concern" (e.g., if the therapist was working with a European American man whose presenting concern was anxiety). These therapists variantly reported that they would not address race if they sensed that the client was uncomfortable with the topic or did not want to discuss the topic. Here, for instance, 1 therapist stated that if she believed discussing race would be an impediment to therapy (e.g., heighten a client's defensiveness), she would not engage in such a discussion. Finally, these therapists also variantly indicated that they would not address race if the issue seemed to come from the therapist's own countertransference (a category that only emerged for African American participants). As an 
example, 1 therapist acknowledged that if she felt she were having a reaction to a client and that her interest in exploring race came from her "own stuff," she would not address race with the client.

Among European American therapists, one typical and one variant category emerged. Similar to the African American therapists, these participants typically did not address race if they felt that it was not an issue in the therapy. As an example, 1 therapist reported that if what his client was discussing felt separate from race, he would not raise race as an issue because doing so might suggest that the therapist was not listening to the client. Again like their African American counterparts, European American therapists variantly reported that they would not address race if they felt that the client would be uncomfortable doing so or did not want to discuss the issue. One therapist, for example, stated that if a client told him that she or he was "so sick" of discussing race, the therapist would not address it.

Perceived Effect of Addressing Race in Psychotherapy: For African American therapists, three typical categories emerged. First, these participants typically reported that addressing race had positive effects on therapy. One respondent indicated that she believed that the therapy relationship may be strengthened when the topic of race is raised and discussed; likewise, another therapist stated that addressing race had been extremely helpful and powerful in his experiences. Second, these therapists typically averred a negative impact on therapy if race is not addressed, or if it is not addressed correctly. As an example, 1 therapist felt that if race was ignored, she could make errors in diagnosis, conceptualization, and treatment, potentially resulting in a "real empathic failure." Another therapist stated that if race was "not raised correctly, it can backfire and the client may feel further alienated from" the therapist. Finally (in a category that did not emerge for European American therapists), these participants typically reported that the effect of addressing race depended on factors such as timing, method, and client defensiveness. As an illustration, 1 therapist stated that addressing race usually had a positive effect, but also acknowledged that the effect depends on clients' racial identity development and level of defensiveness.

Among European American therapists, one typical and one variant category emerged. Like their African American counterparts, 
these therapists indicated that addressing race typically had positive effects on therapy, as exemplified by the therapist who stated that his discussions of race fostered a deeper connection between client and therapist, and another therapist who offered that such discussions can serve "as a tool for change ... an educational opportunity for therapy." These respondents variantly indicated that there could be a negative effect of not addressing race, or of not addressing it correctly. For instance, 1 therapist stated that ignoring race was disrespectful to clients and to the therapy relationship.

Changes in Therapists' Thoughts About Addressing Race in Therapy During Their Careers: One general and one variant category emerged for African American participants. All of these therapists reported now feeling more skilled at and comfortable with addressing race in therapy. One therapist acknowledged that she now makes more informed choices about whether and how to address race. Similarly, another therapist stated that over the course of his career, he has gained knowledge and emotional comfort with openly discussing race in therapy, describing himself now as "more mellow than I was when I was a young man" with respect to his greater ease when discussing race. Variantly, these participants indicated a greater awareness of their need to examine themselves in order to address race in therapy effectively. As described by 1 participant, she now understood the need to have one eye on herself to look at her own reactions to working with a person of a different race, and to use those reactions in the therapy process.

For European American participants, one typical and three variant categories emerged. In contrast to their African American counterparts, these therapists only typically reported an increase in skill or comfort with addressing race in therapy, as illustrated by the participant who stated that he now felt more comfortable and competent to address race as an important clinical issue. In the first variant category, these respondents (like the African American therapists) also asserted an increased awareness of the need to examine themselves in order to address race effectively in therapy. As stated by 1 participant, he sought, through supervisors who would challenge him, to face the issues within himself that get in the way of being present with clients, and has thus been able to move from "a place of fear to a place of acceptance." Neither of the two remaining 
variant categories emerged in the African American sample. First, European American therapists reported more frequently addressing race in therapy as their careers developed. One respondent indicated that he now looked for opportunities to address race more than he did earlier in his career. Finally, this sample variantly reported experiencing no change in their thoughts or feelings about addressing race in therapy, as portrayed by the therapist who stated that she always thought addressing race was important.

Experience of Interview: For African American participants, one general and one variant category emerged. All of these therapists reported that the interview promoted their examination and awareness of racial issues in therapy. One therapist commented, for example, that the interview made her realize that she will "always be a work in progress," and another participant noted that he felt some frustration and anger that racially diverse clients do not get the services they need. These therapists variantly reported feeling anxiety or vulnerability related to their participation. One respondent wondered whether she was trying to appear socially desirable, for instance, and another acknowledged that she became aware of feelings of vulnerability as she discussed "what you do and don't do with clients."

The same categories, again one general and one variant, emerged for the European American participants. All of these therapists also indicated that the interview stimulated their examination and awareness of racial issues in therapy, epitomized by the participant who stated that he found the interview "enlightening" and made him more aware of the impact of his clinical decisions. Variantly, these participants also reported feeling some anxiety or vulnerability. One therapist, for example, noted that the interview triggered some of the feelings that he experienced in particularly difficult cross-racial therapies.

\section{Therapists' Discussion of a Specific Cross-Racial Dyad:} Here we focus on some distinct types of experiences that our participants reported, experiences that may be better understood in the context of the previous findings. First, we present results that emerged when therapists discussed a specific instance of addressing race with a cross-racial client that they perceived to have had a positive effect on the therapy (see Table 2). All 12 therapists reported 
such incidents, and thus we maintain the structure established above (i.e., results from African American participants, followed by results from European American participants). Because not all therapists reported having had the other three types of specific events (i.e., discussion of race that was perceived to have had a negative effect, lack of discussion of race that was perceived to have had a positive effect, lack of discussion of race that was perceived to have had a negative effect), we only briefly summarize those findings.

\section{Discussion of Race That Therapists Perceived to Have Had a Positive Effect on Therapy}

When race was addressed: African American therapists variantly addressed race at the beginning of therapy, and also variantly addressed it toward the middle of therapy. European American therapists, in contrast, typically addressed race early in therapy and variantly addressed race in the middle of therapy.

Why race was addressed: African American participants typically addressed race because they perceived some degree of discomfort in their European American clients. For example, 1 therapist recalled a male client who seemed to be hesitant to bring up his feelings about African Americans trying to "take advantage of affirmative action" policies. The therapist felt it very important to help the client feel comfortable raising such concerns, so she invited him to share his feelings. Variantly, these therapists also discussed race because their clients raised the issue. For instance, 1 therapist discussed with her client the impact on their relationship of the client's feelings of being "one up" on African American students.

European American participants variantly addressed race because they perceived client discomfort. As an example, 1 therapist described a time when his client talked about his involvement in the riots of 1968 . The therapist sensed the client's defensiveness and difficulty discussing such incidents, despite his apparent intense affect, and wondered aloud with the client whether the discomfort was related to the therapist being White and the client being Black. The client acknowledged that this racial difference was indeed contributing to his reticence, for he wondered whether the therapist "might have been one of the racists who was on the other side of the line in the riots." 
European American therapists, as did African American therapists, variantly addressed race when clients raised the issue. One therapist reported that after her client stated that "all of his girlfriends had been White women," the therapist felt it necessary to process with the client his choice of a White woman as a therapist. In a category that emerged only in the European American sample, these therapists variantly reported that they addressed race when clients were struggling with personal versus community expectations. As an illustration, a therapist recalled a client who was experiencing pressure from her family and local community to become a physician. In therapy, they discussed the client's sense of being the "community prize" and the incumbent expectations that she be highly successful.

Therapists' comfort addressing race: Typically, African American therapists reported feeling comfortable addressing race with their clients, whereas European American therapists variantly reported feeling such comfort. European American participants instead typically felt some discomfort, as represented by the therapist who stated that he felt "fear and hesitation" because he was uncertain how the discussion of race would go.

How was race addressed: African American therapists typically addressed race directly, through asking questions or confrontation or immediacy. For example, 1 therapist indicated that she directly asked her client what it was like for her to talk to an African American therapist. These participants also variantly followed their client's lead in addressing race. Here, for instance, after her client discussed her sense of invisibility as a Jewish woman who was perceived as neither Caucasian nor Jewish but often as Mexican American, Middle Eastern, or Iranian, a therapist invited her client to discuss her feelings about being offended and stereotyped and the effects of such racism on the client's identity.

European American therapists also typically addressed race directly, again through questions or confrontation or immediacy. One therapist, for instance, reported asking her client, "You know, I'm a White woman. How do you see that affecting our relationship here?" Again like their African American counterparts, these therapists variantly followed their client's lead in addressing race. For example, 1 
therapist stated that he, in fact, followed his client's lead in listening to and facilitating a discussion of the client's experience of racism.

Effect of addressing race on therapy relationship: All African American therapists reported that this incident had a positive effect on the therapy, whether in the form of increasing rapport, client comfort, or validation of client feelings. More specifically, these therapists also typically reported that such discussions increased the trust and security of the therapy relationship. One therapist, for example, stated that after the discussion, her client was more open and trusting, and the therapy moved to a "deeper level."

Paralleling the African American therapists, all European American participants also reported that the discussion of race had salutary effects on the therapy. And again like their African American counterparts, these therapists typically reported that the discussion of race increased the trust and security of the therapy relationship. One therapist stated that he felt the relationship became "closer and more connected," and another felt that it strengthened the therapeutic alliance.

Discussion of Race That Therapists Perceived to Have Had a Negative Effect on Therapy: Only 3 participants (i.e., 1 African American, 2 European Americans) reported instances in which they discussed race with a client and felt that the discussion had a negative effect on the therapy. Thus, we present these results tentatively. In addition, we discuss both African American and European American therapists' experiences together and do not frame them in terms of general, typical, or variant findings.

Discussions of race that had perceived negative effects on clients seemed to occur early in therapy and arose because therapists felt race was relevant to the clinical process and relationship. There was no clear pattern in terms of how race was addressed: In one case, the client raised the topic of race in the therapy, and in the two other cases, the therapist raised the topic of racial differences between client and therapist. Each therapist perceived the discussion to have elicited negative effects, either in the form of creating distance between therapist and client or of increasing client anxiety. 
NOT THE PUBLISHED VERSION; this is the author's final, peer-reviewed manuscript. The published version may be accessed by following the link in the citation at the bottom of the page.

Lack of Discussion of Race That Therapists Perceived to Have Had a Positive Effect on Therapy: Seven therapists (i.e., 3 African Americans, 4 European Americans) recalled a time when they deliberately chose not to discuss race with a client and perceived this lack of discussion to have had a positive effect on the therapy. Here again, we present these results tentatively and combine the findings for the two participant groups.

These therapists most often reported that they chose not to address race in these cases because they felt it unimportant to the therapy, either because race was not an issue at all or it was much less significant an issue than other (i.e., nonracial) issues with which the client was struggling. In this vein, several therapists stated that there was so much else that clients needed to talk about (e.g., suicidality, psychotic episodes) that a discussion of race seemed irrelevant. Additionally, a few therapists acknowledged that they did not discuss race because their clients had stated that they did not want to talk about race; furthermore, a few therapists stated that they did not discuss race because they feared that doing so would have a negative effect on the therapy. Finally, these therapists asserted that not discussing race had a positive impact on the therapy, either because "it didn't clutter the client's mind with [other] issues" or because in not discussing race, the therapist respected the client's agenda and wishes.

Lack of Discussion of Race That Therapists Perceived to Have Had a Negative Effect on Therapy: Only 3 therapists (i.e., all European American) reported examples when their decision not to discuss race appeared to have had a negative effect on the therapy. They reported choosing not to address race because they were uncertain as to what, if any, connection race had to what was happening in therapy. One therapist, for example, acknowledged that she was struggling to determine whether raising the topic of race reflected her need, or her client's need. These therapists suspected that the omission of a discussion of race had negative effects on the therapy, as exemplified by the therapist who feared that his client may not have felt completely heard or supported by the therapist because race was an important part of the client's identity. 
NOT THE PUBLISHED VERSION; this is the author's final, peer-reviewed manuscript. The published version may be accessed by following the link in the citation at the bottom of the page.

Illustrative Examples of Addressing Race That Therapists Perceived to Have Had a Positive Effect: We provide illustrative examples (i.e., one from an African American therapist, one from a European American therapist) in which therapists perceived that addressing race had a positive effect on the therapy. Each example has been slightly altered to protect confidentiality.

Dr. A, a male African American therapist in his mid-40s who had been in practice for less than 5 years and espoused an eclecticmulticultural theoretical orientation, reported that $90 \%$ of his current clients were of a different race than he, most of whom were European American. Dr. A spoke about "Patricia," a European American female client who was in her mid-30s and who felt marginalized because she grew up poor. She sought therapy for concerns about relationships and low self-esteem related to her SES. Patricia acknowledged midway through therapy "doing a one-up thing in her head," wherein she reported feeling that although she may be poor, at least she was "better than them." When Patricia made this statement, Dr. A perceived some discomfort on her part and sensed that she was "hedging" and was not identifying that those whom she felt better than may have been people of color. Eventually, it became clear that Patricia's "them" were African Americans. Dr. A felt comfortable with Patricia and felt their therapy relationship was stable, so he addressed the racial issues directly by asking Patricia what it was like for her to talk with an African American therapist. Dr. A also normalized her experience of needing to feel powerful over others whom you feel are "under you" when you do not feel good about yourself. After this conversation, Dr. A sensed that Patricia became more comfortable talking about race with him and felt an even stronger connection between therapist and client, which he surmised may have worked to speed up the therapy.

In the second example, Dr. E, a 45-year-old female European American therapist in practice for 5 years, with a feminist/existential/cognitive-behavioral orientation, stated that $10 \%$ of her clients were of a different race (i.e., Asian American, African American, Latina/o) than she. Dr. E described her work with "Chris," an African American college senior in her mid-30s who was wrestling with how much she wished to re-enter her community after graduation. Chris was from an urban area and had opportunities to 
work there; however, she felt that she would have to make sacrifices to return there, such as not being in a higher education environment or not attending graduate school. Early in the therapy, Dr. E raised the topic of race because she was aware that Chris was struggling with her personal versus her community's expectations. Though she felt some trepidation about having such a discussion, Dr. E felt that Chris would benefit from talking to someone who did not have an agenda for her, as Chris perceived her family and friends to have (i.e., her family wanted Chris to return to her community; her friends wanted her to go to graduate school). Thus, Dr. E addressed the issue directly through questions and gentle confrontations and followed Chris's lead as the discussion continued. Chris later thanked Dr. E for being willing to talk about what Chris really needed to talk about, and Dr. E felt this an indication that the discussion had gone well.

\section{Discussion}

\section{Therapists' Overall Experiences With Race}

As a context within which to understand their experiences of a specific cross-racial therapy dyad (see below), we found that more African American than European American therapists reported having had experiences with racially different others prior to graduate school that taught them about race and later influenced their approach to therapy. Such a finding is not surprising, given that African Americans have historically been more likely to find themselves in situations (e.g., school, work, community) in which they are the racial minority. In contrast, some European American therapists acknowledged an early naiveté about or denial of racial differences. With fewer experiences in which they meet or associate with those of a different race, European Americans may be less often confronted with racial differences, and may thus remain unaware of their existence. The early lived experience between these two groups, then, may indeed be quite different, and, in the case of the African American therapists, affected their approach to therapy.

Both African American and European American therapists reported largely similar graduate school didactic experiences that focused on race, for both groups took classes, workshops, and special 
trainings. Interestingly, however, only European American therapists reported receiving minimal or no didactic training that addressed race. This finding is intriguing, for it may be that some European American therapists felt that their admitted naiveté was perpetuated by their didactic graduate training program's perceived scant attention to race. Such a possibility is at least partially supported by the finding that the multicultural survey texts often used in didactic courses pay little attention to racial issues, racial oppression, and power dynamics in the therapy relationship (Neville, Worthington, \& Spanierman, 2001). Similarly, a content analysis of multicultural counseling course syllabi from APA-accredited counseling psychology programs revealed almost no emphasis on skill development (Priester, Jackson-Bailey, Jones, Jordan, \& Metz, 2003). Given their different lived experiences (see above), perhaps the European American therapists looked toward their graduate training to provide them knowledge and skill development considered helpful for working with racially different clients. Our results suggest that they did not find all that they were looking for in these courses. Although the vast majority (i.e., 89\%) of APA-approved counseling psychology programs offer a multicultural course (Hills \& Strozier, 1992), we do not know whether these respondents were students in the $11 \%$ of programs that reportedly do not offer such courses.

With regard to supervision and practica in graduate school, these participants reported largely similar experiences: They saw clients of different races, addressed multiculturalism in supervision, and took part in multicultural training activities. Consistent with the prior finding, however, more European American than African American therapists reported receiving little or no supervision or practica experiences related to race. The lack of such experiences may also help explain the later finding that European American therapists reported greater discomfort addressing race in the specific cross-racial therapy dyad than did their African American counterparts: If the former received less training and had less clinical experience regarding race, they may well have felt discomfort when addressing the topic in an actual psychotherapy dyad.

The most striking difference here, though, is the following: Whereas no European American participants reported negative experiences as supervisees or practicum students related to race, most 
African American participants attested to having had such experiences. They spoke of feeling that they were presumed to represent their entire race, of fearing disagreement with their supervisors, and of having to alter their therapy interventions to avoid negative stereotypical perceptions. Such difficult circumstances may have engendered in the African American participants a greater sensitivity for discomfort, whether their own or others'. Perhaps this sensitivity was then manifested in their more often addressing racial issues in the cross-racial dyad because they sensed client discomfort than did their European American peers.

After graduate school, the experiences of the two groups of participants diverged further. All of the African American, and none of the European American, therapists indicated that they had attended multicultural workshops or conferences; likewise, the former were involved in conducting multicultural training sessions and had experiences with those of a different race in their first postgraduate position, whereas their counterparts did not. Similar to the duringgraduate school findings, only European American therapists reported minimal or no postgraduate experiences that focused on race. Here again, then, the European American psychologists' comparatively fewer experiences that focused on race may contribute to their greater reported discomfort addressing race in the cross-racial dyad they described. If these results are not idiosyncratic to these participants, but instead reflect larger patterns among African American and European American therapists, they suggest a trend of some concern. European American therapists may enter graduate school comparatively unaware of racial differences; may or may not receive multicultural training in graduate school that addresses racial issues; and upon leaving graduate school, may encounter or seek out even fewer training experiences that address working with racially different clients. Given the changing demographics in the United States (i.e., $25 \%$ of the U.S. population consisted of ethnic minorities in the year 2000 ; by 2050 , the ethnic minority population is estimated to exceed $50 \%$; U.S. Department of Commerce, 2001), it is increasingly likely that all therapists will work with clients racially different from themselves. As such, they need appropriate training to work effectively with these clients. 
When they did address race with racially different clients, both African American and European American therapists usually did so when they considered the issue to be relevant to therapy. However, only African American therapists reported raising race when actually working with clients of color. It seems, then, that these African American therapists customarily addressed race with non-European American clients, but the European American therapists did not do so as a matter of routine. It is possible that their relatively rarer training experiences focusing on race (see above), and the potential unease borne of such minimal experience, again help explain these results. Relatedly, although some European American therapists indicated that if a client initiated a discussion of race, they would respond, some also asserted that they would not normally discuss race. Such a finding is intriguing in light of Thompson and Jenal's (1994) finding that female African American pseudoclients who raised racial issues in therapy became frustrated and exasperated with counselors who avoided racial content, suggesting that avoidance, or possibly lack, of a discussion of racial content may have a deleterious effect on therapy. Addressing race with clients of color was nevertheless a less frequent experience for these European American than for African American therapists. Perhaps the former felt less comfortable addressing a topic that they perceived to have the potential to be quite difficult, a finding echoed by Utsey and Gernat (2002). Alternatively, based on their reported graduate training, perhaps they remained relatively unaware of the impact of race and thus saw no reason to broach the topic.

Whatever the frequency of addressing race, both African American and European American therapists largely perceived that when such discussions occurred, they had a positive effect on therapy, a finding that echoes earlier research (e.g., Atkinson et al., 1992; Atkinson \& Lowe, 1995; Boyd-Franklin, 1989; Fuertes et al., 2002; Gim et al., 1991; Helms, 1984; Pinderhughes, 1989; Pomales et al., 1986; Sue \& Sue, 2002; Thompson et al., 1994; Wade \& Bernstein, 1991; Zhang \& Burkard, 2002). African American (and not European American) therapists, however, often remarked that negative effects could arise if race was not addressed correctly, or was not addressed at all, a finding that also parallels earlier research (e.g., Thompson \& Jenal, 1994). Here again emerges an apparent greater emphasis on addressing race among the African American participants. As persons who may have been the recipients of racially biased treatment, 
perhaps these therapists had developed a greater attunement to the impact of either not discussing race or not discussing it effectively.

All of the African American participants, and most of the European American participants, indicated that they now felt more skilled and more comfortable addressing race, as compared with earlier in their professional careers. Perhaps accumulated experience of working with clients, and specifically with racially different clients, as well as experience discussing race explains this greater sense of confidence. Interestingly, only European American therapists reported that they now addressed race more frequently than they did earlier in their careers. It could be that they now work with greater numbers of racially different clients, or such a finding could also be related to their greater comfort, as described above. We did not explicitly ask respondents what accounted for these changes, so we can only conjecture as to their causes.

As they discussed their experience of the interview, these two groups' responses were quite similar: All noted that the interview stimulated their own examination and awareness of racial issues in therapy, and some participants from each group acknowledged feeling discomfort during the interview process. When describing their experiences, then, the participants admittedly found the process to be thought-provoking. Yet some degree of discomfort was reported, suggesting that this may still be a difficult topic for some to discuss. The extent to which this discomfort may have affected the findings is unknown.

\section{Therapists' Discussion of a Specific Cross-Racial Dyad}

When describing a specific example of a cross-racial dyad, European American participants reported discussing race early in therapy more often than did their African American counterparts. This result is intriguing, given some of the other findings related to European American therapists (i.e., they often had minimal or no supervision or practicum experiences that focused on addressing race while in graduate school; they did not report attending multicultural workshops or conferences after graduation, nor conducting multicultural training sessions; they often had minimal if any postgraduation supervision that focused on race; they did not report 
any regular pattern of raising the topic of race with clients of color; and some reported that they did not normally discuss race). How, then, do we make sense of these results? It may be that when European American therapists address race with African American clients, regardless of the extent of their training experiences they do so fairly early in therapy, perhaps in an effort to put obvious differences between themselves and their clients on the table and communicate an openness to such discussions. Perhaps, also, because many of these therapists reported feeling more comfortable and more skilled addressing race now than they did earlier in their career, the dyad they chose to discuss here was one that had occurred more recently, and thus may reflect this greater degree of comfort, which may have facilitated addressing the topic of race early in therapy.

As reasons for addressing race in these dyads, African American more often than European American therapists did so because they perceived discomfort in their clients. Perhaps because of their own history of often being in the minority, African American therapists were more attuned to noting when others seemed uncomfortable around them (Sue \& Sue, 2002). Relatedly, because they are often in the majority and live in a society that still largely considers their experience the norm, European American therapists may have been less attuned to their clients' discomfort. It is also possible that the clients seen by the African American therapists had never worked with a professional of a different race, and the therapists then accurately perceived their clients' potential feelings of unease. Interestingly, only European American therapists reported addressing race because they sensed that their clients were struggling with community versus personal expectations. This finding may reflect the continuing struggle faced by some African Americans to navigate between potentially competing demands or expectations (e.g., personal vs. cultural). Recall, for example, the therapist who described his client's sense of being the community prize, a label that carried with it pressure to be successful in a demanding career (i.e., medicine). The client clearly felt the expectations and hopes of her community, expectations that may not have matched her own personal goals but that she respected because of the importance of her community. If the community prize chose to pursue another career, she may well fear that she will have disappointed that very community. 
NOT THE PUBLISHED VERSION; this is the author's final, peer-reviewed manuscript. The published version may be accessed by following the link in the citation at the bottom of the page.

More African American therapists felt comfortable addressing race in these dyads than did European American therapists. Possibly more interesting, however, is the finding that most European American therapists, and no African American therapists, reported discomfort with such discussions. Again, perhaps because of differing life or training experiences (e.g., African American therapists often being in the minority and having to negotiate racial differences regularly, whereas European American therapists' usual position in the majority may lead to fewer opportunities to work through racial differences; European American therapists more often reporting minimal or no attention to race in their training), the former are more familiar with, and thereby possibly more comfortable, discussing race than the latter. As suggested by one of our participants, European American therapists may have felt some trepidation about how such a discussion would go, as well as how their clients might receive it. Pulling some of the findings together about these specific cross-racial dyads, African American therapists more than European American therapists addressed race because they perceived discomfort in their clients, and evidently felt comfortable doing so. European American therapists, in contrast, less often noted client discomfort as a reason for addressing race but clearly acknowledged their own discomfort with such discussions. Were they more attuned to their own responses and reactions when working with African American clients, and thus less able to attend to potential client discomfort and needs? Had their training experiences more closely paralleled those of their African American counterparts, would they have felt greater comfort and been more able to attend to their clients? These questions pose interesting possibilities.

African American and European American therapists reported similar patterns with respect to how they addressed race in these particular dyads and the perceived effects of doing so: Most addressed race directly, and all felt that these discussions led to positive effects, which often included enhanced trust in the relationship. When actually engaging in such discussions, then, these therapists tended to broach the topic of race openly and overtly and found the effects to be beneficial. These perceived salutary effects on the therapy relationship support earlier theorists' view of the importance of cultural responsiveness, including race, in cross-cultural therapy (e.g., Atkinson \& Lowe, 1995; Boyd-Franklin, 1989; Helms, 1984; 
Pinderhughes, 1989; Sue \& Sue, 2002) and are also consistent with extant empirical research (Fuertes et al., 2002; Thompson \& Jenal, 1994; Thompson et al., 1994; Zhang \& Burkard, 2002).

\section{Limitations}

These results are limited to this sample of 12 licensed psychologists who volunteered to participate in this study. Therefore, these findings may not be reflective of those who were aware of the study but chose not to participate. The size of the final sample is, however, consistent with the methodology's guidelines (Hill et al., 1997). We were able to balance the sample by gender but acknowledge that we have more European American than African American participants, which is most likely an artifact of the difficulty we encountered acquiring our sample. Additionally, some participants switched back and forth within the course of the interview between a broad definition of multiculturalism and a more specific focus on race, a phenomenon that reflects the very debate within our field regarding the definition of multiculturalism (Carter, 1995; Helms \& Richardson, 1997). When discussing their overall experiences with race, for example, some seemed to be focusing on this broader definition, whereas when they discussed a specific cross-racial dyad, they more consistently focused on race alone. Furthermore, although all participants were asked to describe four distinct events (i.e., discussion of race perceived to have had positive effects; discussion of race perceived to have had negative effects; lack of discussion perceived to have had positive effects; lack of discussion perceived to have had negative effects), few actually reported the latter three types. Perhaps they were reluctant to discuss experiences they considered to have had a negative impact on therapy; perhaps, also, it was difficult to recall a specific example of not doing something (i.e., discussing race). In addition, these results are based on what participants spontaneously reported when responding to the protocol questions. We also have only the therapists' perspectives here, and thus do not know the effect of these experiences on clients. In addition, we cannot discount the possibility that differences in our participants' years of experience as therapists, and as therapists with racially different clients, may also have contributed to the findings. Finally, we included the interview protocol in the initial mailing so that participants could provide fully informed consent, and could also think 
NOT THE PUBLISHED VERSION; this is the author's final, peer-reviewed manuscript. The published version may be accessed by following the link in the citation at the bottom of the page.

about their relevant experiences if they chose to participate in the study. We acknowledge that awareness of the interview questions, although possibly facilitating richer responses, may also have allowed participants to alter their comments to appear socially desirable (Hill et al., 1997).

\section{Implications}

Among the intriguing differences that emerged between the African American and European American participants is the sense of lived experience of race versus academic learning about race. The African American participants appeared quite vividly to be engaged in cross-racial encounters throughout their lives. The European American therapists, however, seemed to have a more distant point of reference for racial differences in that what learning they acquired about how to work with those of a different race came not from actual experience but instead from the academy; even within the academy, such learning was also frequently reported as minimal. In addition, the African American participants reported not only slightly more years of experience as therapists but also more work with racially different clients. From such experiential differences may arise important subtle distinctions between how African American and European American therapists actually address racial content in therapy, distinctions that could not be assessed in the present study. Examination of therapist and client interactions may thus be a prudent step to investigate actual discussions of race in cross-racial dyads. Furthermore, the field may benefit from future research that examines more narrowly defined samples of therapists, such as those at a distinct experience level or age range, to assess the effects of experience and age on how therapists address race. Likewise, researchers could investigate how therapists' addressing or not addressing racial issues with cross-racial clients develops over the course of their careers. Relatedly, the present study captures only therapists' reports of such events. It is possible that clients' perceptions of discussions of race may differ from therapists' (Ponterotto \& Casas, 1991). We need, then, to allow clients to have an equal voice as we seek to understand this phenomenon.

In addition, we note that only African American therapists reported having negative experiences related to race while in graduate supervision or practica (these therapists had been in graduate school 
recently). Such reports also call for further investigation, for they raise concerns about students' graduate school experiences (D'Andrea \& Daniels, 2001; D'Andrea et al., 2001). Similarly, only African American therapists reported having consistent postgraduate experiences with racially different individuals, whether those experiences be in didactic or supervisory realms. This finding raises important questions: What appears to foster these therapists' involvement in such opportunities? Likewise, what may be inhibiting European American therapists from engaging in similar activities? And how do such training experiences translate into actual therapy practice? These questions must be addressed if we wish to nurture all therapists' development and competence.

Finally, all African American and most European American therapists reported that they felt both more skilled and more comfortable addressing race now than they did earlier in their careers. We do not know, however, what accounts for this growth. Identifying those factors that appear to enhance therapists' willingness and ability to address race in therapy could aid in the training and supervision of present and future therapists.

Thus, although this study adds to our understanding of therapists' experiences of addressing race in cross-racial dyads, there is clearly much more that remains to be learned. Furthermore, given the changing demographics of the U.S. population, we support the position of La Roche and Maxie (2003), who assert that it is incumbent upon all therapists to be prepared to work with those racially different from themselves. We then encourage others to explore the questions we have herein raised and to continue to ask additional questions, so that with deeper understanding we may serve our clients better.

\section{References}

American Psychological Association. (1993). Guidelines for providers of psychological services to ethnic, linguistic, and culturally diverse populations. American Psychologist, 48, 45-48.

American Psychological Association. (2003). Guidelines on multicultural education, training, research, practice, and organizational change for psychologists. American Psychologist, 58, 377-402. 
NOT THE PUBLISHED VERSION; this is the author's final, peer-reviewed manuscript. The published version may be accessed by following the link in the citation at the bottom of the page.

Atkinson, D. R., Casas, A., \& Abreu, J. (1992). Mexican-American acculturation, counselor ethnicity and cultural sensitivity, and perceived counselor competence. Journal of Counseling Psychology, $39,515-520$.

Atkinson, D. R., \& Lowe, S. M. (1995). The role of ethnicity, cultural knowledge, and conventional techniques in counseling and psychotherapy. In J. G.Ponterotto, J. M.Casas, L.A., Suzuki, \& C. M.Alexander (Eds.), Handbook of multicultural counseling (pp. 387414). Thousand Oaks, CA: Sage.

Boyd-Franklin, N. (1989). Black families in therapy: A multisystems approach. New York: Guilford Press.

Burkard, A. W., Juarez-Huffaker, M., \& Ajmere, K. (in press). White racial identity attitudes as a predictor of client perceptions of cross-cultural working alliances. Journal of Multicultural Counseling and Development.

Burkard, A. W., Ponterotto, J. G., Reynolds, A. L., \& Alfonso, V. C. (1999). White counselor racial identity attitudes and working alliance perceptions. Journal of Counseling and Development, 77, 324-329.

Carter, R. T. (1995). The influence of race and racial identity in psychotherapy: Toward a racially inclusive model. New York: Wiley.

D'Andrea, M., \& Daniels, J. (2001). Expanding our thinking about White racism: Facing the challenge of multicultural counseling in the 21st century. In J. G.Ponterotto, J. M.Casas, L.A., Suzuki, \& C. M.Alexander (Eds.), Handbook of multicultural counseling (2nd ed., (pp. 289-310). Thousand Oaks, CA: Sage.

D'Andrea, M., Daniels, J., Arredondo, P., Ivey, M. B., Ivey, A. E., Locke, D. C., et al. (2001). Fostering organizational changes to realize the revolutionary potential of the multicultural movement: An updated case study. In J. G.Ponterotto, J. M.Casas, L.A., Suzuki, \& C. M.Alexander (Eds.), Handbook of multicultural counseling (2nd ed., (pp. 222-253). Thousand Oaks, CA: Sage.

Fuertes, J. N., \& Gretchen, D. (2001). Emerging theories of multicultural counseling. In J. G.Ponterotto, J. M.Casas, L.A., Suzuki, \& C. M.Alexander (Eds.), Handbook of multicultural counseling (2nd ed., (pp. 509-541). Thousand Oaks, CA: Sage. American Psychological Association does not grant permission for this article to be further copied/distributed or hosted elsewhere without the express permission from American Psychological Association. 
NOT THE PUBLISHED VERSION; this is the author's final, peer-reviewed manuscript. The published version may be accessed by following the link in the citation at the bottom of the page.

Fuertes, J. N., Mueller, L. N., Chauhan, R. V., Walker, J. A., \& Ladany, N. (2002). An investigation of European American therapists' approach to counseling African American clients. The Counseling Psychologist, 30, 763-788.

Gim, R. H., Atkinson, D. R., \& Kim, S. J. (1991). Asian-American acculturation, counseling ethnicity and cultural sensitivity and ratings of counselors. Journal of Counseling Psychology, 38, 57-62.

Helms, J. E. (1984). Towards a theoretical explanation of the effects of race on counseling: A Black and White model. The Counseling Psychologist, $12,153-165$.

Helms, J. E. (1995). An update of Helms's White and People of Color racial identity models. In J. G.Ponterotto, J. M.Casas, L. A.Suzuki, \& C. M.Alexander (Eds.), Handbook of multicultural counseling (2nd ed., (pp. 181-198). Thousand Oaks, CA: Sage.

Helms, J. E., \& Cook, D. A. (1999). Using race and culture in counseling and psychotherapy. Boston: Allyn \& Bacon.

Helms, J. E., \& Richardson, T. Q. (1997). How "multiculturalism" obscures race and culture as differential aspects of counseling competency. In D. B.Pope-Davis, \& H. L. K.Coleman (Eds.), Multicultural counseling competencies: Assessment, education and training, and supervision (pp. 60-79). Thousand Oaks, CA: Sage.

Hill, C. E., Thompson, B. J., \& Williams, E. N. (1997). A guide to conducting consensual qualitative research. The Counseling Psychologist, 25, 517572.

Hills, H. I., \& Strozier, A. A. (1992). Multicultural training in APA-approved counseling psychology programs: A survey. Professional Psychology: Research and Practice, 23, 43-51.

La Roche, M. J., \& Maxie, A. (2003). Ten considerations in addressing cultural differences in psychotherapy. Professional Psychology: Research and Practice, 34, 180-186.

Miles, M. B., \& Huberman, A. M. (1994). Qualitative data analysis: An expanded sourcebook (2nd ed.). Thousand Oaks, CA: Sage. 
NOT THE PUBLISHED VERSION; this is the author's final, peer-reviewed manuscript. The published version may be accessed by following the link in the citation at the bottom of the page.

Neville, H. A., Worthington, R. L., \& Spanierman, L. B. (2001). Race, power, and multicultural counseling psychology: Understanding White privilege and color-blind racial attitudes. In J. G.Ponterotto, J. M.Casas, L.A., Suzuki, \& C. M.Alexander (Eds.), Handbook of multicultural counseling (2nd ed., (pp. 257-288). Thousand Oaks, CA: Sage.

Pinderhughes, E. (1989). Understanding race, ethnicity, and power: The key to efficacy in clinical practice. New York: Free Press.

Pomales, J., Claiborn, C. D., \& Lafromboise, T. D. (1986). Effects of Black students' racial identity on perceptions of White counselors varying in cultural sensitivity. Journal of Counseling Psychology, 33, 57-61.

Ponterotto, J. G. (2002). Qualitative research methods: The fifth force in psychology. The Counseling Psychologist, 30, 394-406.

Ponterotto, J. G., \& Casas, J. M. (1991). Handbook of racial/ethnic minority counseling research. Springfield, IL: Charles C Thomas.

Ponterotto, J. G., Fuertes, J. N., \& Chen, E. (2000). Models of multicultural counseling. In S. E.Brown \& R. W.Lent (Eds.), Handbook of counseling psychology (3rd ed., (pp. 639-669). New York: Wiley.

Priester, P. E., Jackson-Bailey, C. M., Jones, J. E., Jordan, E. X., \& Metz, A. J. (2003). An analysis of content and instructional strategies in APAaccredited counseling psychology multicultural counseling courses.Manuscript submitted for publication.

Sue, D. W., \& Sue, D. (2002). Counseling the culturally different: Theory and practice (4th ed.). New York: Wiley.

Thompson, C. E., \& Jenal, S. T. (1994). Interracial and intraracial quasicounseling interactions when counselors avoid discussing race. Journal of Counseling Psychology, 41, 484-491.

Thompson, C. E., Worthington, R., \& Atkinson, D. R. (1994). Counselor content orientation, counselor race, and Black women's cultural mistrust and self-disclosures. Journal of Counseling Psychology, 41, 155-161.

U.S. Department of Commerce. (2001). Current population survey, 1998, 1999, and 2000. Washington, DC: U.S. Government Printing Office. American Psychological Association does not grant permission for this article to be further copied/distributed or hosted elsewhere without the express permission from American Psychological Association. 
NOT THE PUBLISHED VERSION; this is the author's final, peer-reviewed manuscript. The published version may be accessed by following the link in the citation at the bottom of the page.

Utsey, S. O., \& Gernat, C. A. (2002). White racial identity attitudes and the ego defense mechanisms used by White counselor trainees in racially provocative counseling situations. Journal of Counseling and Development, 80, 475-483.

Wade, P., \& Bernstein, B. L. (1991). Culture sensitivity training and counselor's race: Effects on Black female clients' perceptions and attrition. Journal of Counseling Psychology, 38, 9-15.

Wilkinson, D. (1993). Family ethnicity in America. In H. P.McAdoo (Ed.), Family ethnicity: Strength in diversity (pp. 15-59). Newbury Park, CA: Sage.

Zhang, N., \& Burkard, A. W. (2002). Counselor/client discussions of racial difference and the effect on client working alliance ratings.Manuscript submitted for publication.

Journal of Counseling Psychology, Vol. 50, No. 4 (October 2003): pg. 466-481. DOI. This article is (C) American Psychological Association and permission has been granted for this version to appear in e-Publications@Marquette. American Psychological Association does not grant permission for this article to be further copied/distributed or hosted elsewhere without the express permission from American Psychological Association. 
NOT THE PUBLISHED VERSION; this is the author's final, peer-reviewed manuscript. The published version may be accessed by following the link in the citation at the bottom of the page.

\section{APPENDIX}

\section{Table 1}

Domains, Categories, and Frequencies of Therapists' Overall Experiences With Race

\begin{tabular}{|c|c|c|c|c|}
\hline & Domain & Category & $\begin{array}{l}\text { Frequency } \\
\text { AA }\end{array}$ & $\begin{array}{l}\text { Frequency } \\
\text { EA }\end{array}$ \\
\hline \multirow[t]{3}{*}{1.} & Pregraduate school & Such experiences taught therapist about race & General & Typical \\
\hline & $\begin{array}{l}\text { experiences with racially } \\
\text { different individuals }\end{array}$ & $\begin{array}{l}\text { Such experiences influenced therapists' approach to } \\
\text { therapy }\end{array}$ & Variant & - \\
\hline & & $\begin{array}{l}\text { Awareness of early nalvete/denial toward racial } \\
\text { issues }\end{array}$ & - & Variant \\
\hline \multirow[t]{9}{*}{2.} & $\begin{array}{l}\text { Experiences regarding } \\
\text { racially different individuals } \\
\text { during gracuate school }\end{array}$ & & & \\
\hline & Didactic & Classes that focused on MC issues & Typical & Typical \\
\hline & & Workshops/special training on MC issues & Variant & Typical \\
\hline & & Minimalino class experiences addressing race & - & Variant \\
\hline & Supervision/practicum & Had experiences with MC clierts & Typical & Typical \\
\hline & & Had negative experiences related to race & Typical & - \\
\hline & & Had MC experiences in supervision & Variant & Variant \\
\hline & & Participated in MC training activities & Variant & Variant \\
\hline & & $\begin{array}{l}\text { Minimalino supervisionjpracticum experiences } \\
\text { addressing race }\end{array}$ & Variant & Typical \\
\hline \multirow[t]{6}{*}{3} & $\begin{array}{l}\text { Postgracuate school } \\
\text { experiences with racially } \\
\text { different individuals }\end{array}$ & & & \\
\hline & Didactic & MC workshop/corferences & General & - \\
\hline & & Conducted MC training sessions & Typical & - \\
\hline & & Minimalino supervision focusing on race & - & Variant \\
\hline & Supervision & Had MC experiences in postgrad position & Typical & - \\
\hline & & Minimalino supervision focusing on race & - & Typical \\
\hline \multirow[t]{5}{*}{4.} & When therapists address & When relevant to therapy & General & Typical \\
\hline & race & Raises race with clients of color & Typical & - \\
\hline & & When part of client's presenting cancern & Variant & - \\
\hline & & If client raised race, therapist would discuss & - & Variant \\
\hline & & Would not normally dscuss race & - & Variant \\
\hline \multirow[t]{3}{*}{5} & When therapists do not & If race not an issue in therapy & Typical & Typical \\
\hline & address face & If client uncomfortable with topic & Variant & Variant \\
\hline & & If issue emerged from therapists' countertransference & Variant & - \\
\hline \multirow[t]{3}{*}{6.} & Perceived effect of & Positive & Typical & Typical \\
\hline & addressing race & $\begin{array}{l}\text { Negative effect if not addressedif not addressed } \\
\text { correctly }\end{array}$ & Typical & Variant \\
\hline & & Effect depended on other factors & Typical & - \\
\hline \multirow[t]{4}{*}{7.} & Changes in therapists' & Now more skilled/comfortable addressing race & General & Typical \\
\hline & $\begin{array}{l}\text { thoughts about addressing } \\
\text { race during their careers }\end{array}$ & $\begin{array}{l}\text { Greater awareness of need to examine self to } \\
\text { address race effectively }\end{array}$ & Variant & Variant \\
\hline & & Now address race more frequently & - & Variant \\
\hline & & No change & - & Variant \\
\hline \multirow[t]{2}{*}{8.} & Experience of interview & $\begin{array}{l}\text { Promoted examinationvawareness of racial issues in } \\
\text { therapy }\end{array}$ & General & General \\
\hline & & Provoked anciety/vulnerability & Variant & Variant \\
\hline
\end{tabular}

\section{Interview Protocol}

\section{Opening and Initial Context Questions}

1. What is your definition of multiculturalism?

Probes: What dimensions or aspects of the person does this include (e.g., ethnicity, race, culture, gender, disability, religion, SES, age, sexual orientation)? What role does race have in your definition?

Journal of Counseling Psychology, Vol. 50, No. 4 (October 2003): pg. 466-481. DOI. This article is (C) American Psychological Association and permission has been granted for this version to appear in e-Publications@Marquette. American Psychological Association does not grant permission for this article to be further copied/distributed or hosted elsewhere without the express permission from American Psychological Association. 
NOT THE PUBLISHED VERSION; this is the author's final, peer-reviewed manuscript. The published version may be accessed by following the link in the citation at the bottom of the page.

(A definition of race was then provided for participants [i.e., "a category of persons who are related by a common heredity or ancestry and who are perceived and responded to in terms of external features or traits"; Wilkinson, 1993].)

2. Please describe the experiences you completed during your graduate education specifically addressing racial issues in therapy?

Probes: Didactic/Non-practicum related? Supervision/ Practicum/Experiential? Personal?

3. Please describe the experiences you completed during your postgraduate education specifically addressing racial issues in therapy?

Probes: Didactic/Non-experiential? Supervision/Experiential? Personal?

4. What types of experiences did you have prior to beginning your graduate education that affect your approach to race in therapy?

5. How useful have these training and personal experiences been to your approach to race in therapy?

6. How does bringing race or racial issues into the content (i.e., race as related to a presenting concern) and/or the process (i.e., race as related to the therapist/client relationship) of the therapy interaction affect the therapeutic relationship?

7. Describe general types of situations in which you would address race in psychotherapy? Why?

8. Describe general types of situations in which you would not address race in psychotherapy? Why?

9. Looking at ten of your most recent cross-racial cases (i.e., AfricanAmerican and Caucasian cross-racial dyads), in how many were racial issues raised as a content issue (i.e., race as related to a presenting concern)? As a process issue (i.e., race as related to the therapist/client relationship)? 
NOT THE PUBLISHED VERSION; this is the author's final, peer-reviewed manuscript. The published version may be accessed by following the link in the citation at the bottom of the page.

\section{Critical Incident Questions}

Road map: We're going to be asking you for two incidents when you did address racial issues in therapy (i.e., African-American and Caucasian cross-racial dyads), one when it went well and one when it didn't; then we'll ask you for two incidents when you did not address cross-racial issues in therapy (i.e., AfricanAmerican and Caucasian cross-racial dyads), again one when it went well and one when it didn't.

10. Please describe a time when your addressing racial issues in therapy with a client had a positive effect on the work/relationship. Explain fully.

Probes:

$C$ demographics, including $d x$ When in therapy was race addressed?

What made you think that race was an issue in this case (versus other dimensions of the person)?

Why chose to address it?

How did you address it?

How did client respond?

How was it for you to address racial issues?

How did the conversation affect the therapy relationship?

Would you address racial issues in a similar situation again?

Why/why not?

What, if anything, would you change about how you addressed racial issues in this situation?

When in your career did this incident occur?

11. Please describe a time when your addressing racial issues in therapy with a client had a negative effect on the work/relationship. Explain fully.

Probes:

C demographics, including $d x$

When in therapy was race addressed?

What made you think that race was an issue in this case (versus other dimensions of the person)?

Why chose to address it?

How did you address it?

How did client respond?

How was it for you to address racial issues?

Journal of Counseling Psychology, Vol. 50, No. 4 (October 2003): pg. 466-481. DOI. This article is (c) American Psychological Association and permission has been granted for this version to appear in e-Publications@Marquette. American Psychological Association does not grant permission for this article to be further copied/distributed or hosted elsewhere without the express permission from American Psychological Association. 
NOT THE PUBLISHED VERSION; this is the author's final, peer-reviewed manuscript. The published version may be accessed by following the link in the citation at the bottom of the page.

How did the conversation affect the therapy relationship? Would you address racial issues in a similar situation again? Why/why not?

What, if anything, would you change about how you addressed racial issues in this situation?

How did this incident affect you as a therapist and how did it affect how you approach similar situations in the future? When in your career did this incident occur?

12. Please describe a time when your not addressing racial issues in therapy with a client had a positive effect on the work/relationship. Explain fully.

Probes:

C demographics, including $d x$ What made you think that race was an issue in this case (versus other dimensions of the person)?

Why chose not to address racial issues?

How did this decision affect the therapy relationship?

Would you make the same decision in a similar situation again? Why/why not?

When in your career did this incident occur?

13. Please describe a time when your not addressing racial issues in therapy with a client had a negative effect on the work/relationship. Explain fully.

Probes:

C demographics, including $d x$ What made you think that race was an issue in this case (versus other dimensions of the person)?

Why did you choose not to address racial issues?

How did this decision affect the therapy relationship?

Would you make the same decision in a similar situation again? Why/why not?

How did this incident affect you as a therapist and how did it affect how you approach similar situations in the future? When in your career did this incident occur? 
NOT THE PUBLISHED VERSION; this is the author's final, peer-reviewed manuscript. The published version may be accessed by following the link in the citation at the bottom of the page.

\section{Broader Questions}

14. How have your thoughts and feelings about or approach to addressing race or racial issues in therapy changed over the course of your doing therapy?

15. What advice would you give to those in the field and/or involved in training regarding addressing race or racial issues in therapy?

16. How has it been for you to do this interview? What thoughts and feelings have been evoked by this experience?

17. Any final thoughts, words of wisdom on this topic? 